\title{
Integration Is Correlated With Mental Health Help-Seeking From the General Practitioner: Syrian Refugees' Preferences and Perceived Barriers
}

\author{
Samantha Marie Harris ${ }^{1 *}$, Gro M. Sandal ${ }^{1}$, Hege H. Bye ${ }^{1}$, Lawrence A. Palinkas ${ }^{2}$ and \\ Per-Einar Binder ${ }^{3}$ \\ ${ }^{1}$ Department of Psychosocial Science, Faculty of Psychology, University of Bergen, Bergen, Norway, ${ }^{2}$ Suzanne \\ Dworak-Peck School of Social Work, University of Southern California, Los Angeles, CA, United States, ${ }^{3}$ Department of \\ Clinical Psychology, Faculty of Psychology, University of Bergen, Bergen, Norway
}

\section{OPEN ACCESS}

Edited by:

Claude-Hélène Mayer

University of Johannesburg,

South Africa

Reviewed by:

Ameer Kakaje,

Faculty of Medicine of Damascus

University, Syria

Saba Safdar,

University of Guelph, Canada

*Correspondence:

Samantha Marie Harris samantha.harris@uib.no

Specialty section:

This article was submitted to

Public Mental Health,

a section of the journal

Frontiers in Public Health

Received: 16 September 2021 Accepted: 10 November 2021 Published: 30 November 2021

Citation:

Harris SM, Sandal GM, Bye HH,

Palinkas LA and Binder PE (2021) Integration Is Correlated With Mental Health Help-Seeking From the General

Practitioner: Syrian Refugees'

Preferences and Perceived Barriers.

Front. Public Health 9:777582.

doi: 10.3389/fpubh.2021.777582
Despite a seemingly higher need, refugees in Europe tend to underuse mental health $(\mathrm{MH})$ services. To better understand this underuse, it is important to understand refugees' willingness and ability to seek help from their general practitioner (GP) when experiencing $\mathrm{MH}$ problems. We employed a combined vignette and survey design to explore how the GP fits into the larger context of help-seeking preferences among a sample of Syrian refugees in Norway $(n=92)$, and what barriers they perceive in accessing help from the GP. We also examined how indicators of integration relate to seeking help from the GP. We take an exploratory approach. Participants were presented a vignette of an individual with symptoms in line with ICD-10 and DSM-5 criteria for depression. Participants were somewhat likely to seek help from the GP; however, seeking help from one's relationship with Allah/God and one's partner was preferred. Furthermore, while the GP was rated a somewhat likely help-seeking source, most participants indicated an average of two barriers to seeking help from the GP. Finally, social ties to the majority population in the form of social integration and feelings of connectedness with the host country (psychological integration) were positively correlated with likelihood of seeking help from the GP. Taken together, these findings suggest that the GP is considered a viable source of help among Syrians with a refugee background in the current sample, but that this may be influenced by perceived barriers and social as well as psychological integration. Addressing these barriers and promoting psychosocial integration with the host country are key to facilitating access and usage amongst refugees in need of $\mathrm{MH}$ services.

Keywords: integration, help-seeking, mental disorders, Syrian, refugees, general practice

\section{INTRODUCTION}

Despite a seemingly higher need for mental health (MH) support, refugees in Europe tend to underuse MH services (1). To better understand this underuse, it is important to better understand factors that influence refugees' willingness and ability to seek help from their general practitioner (GP) when experiencing MH problems. Throughout Europe, GPs are often the first line of contact 
for people seeking mental and physical healthcare (2, 3). GPs are trained to manage mild to moderate cases of $\mathrm{MH}$ problems (within primary care) and play a large role in determining appropriate preliminary diagnoses, assessments, treatments, and referrals for patients. Importantly, GPs are also often the first line of contact for patients with a refugee background.

One of the largest groups of refugees to arrive in Europe during the 2015-2016 refugee crisis originated from Syria. Syrian refugees who migrated to Europe and neighboring countries in the Middle East have reported experiences including civil war, torture, cultural integration issues, the loss of family and community support, discrimination and adverse political climate, loneliness and boredom, prohibition to work, and disruption of education for their children (4-6). Such stressors can place refugees at considerable risk of developing symptoms of depression, anxiety, post-traumatic stress disorder (PTSD) and related somatic health symptoms (7-12).

Considering $\mathrm{MH}$ and help-seeking in Syria may place refugees' engagement with health services in Europe into context. However, studies examining the $\mathrm{MH}$ burden in Syria are highly heterogeneous. A recent systematic review of the burden of mental disorders and access to $\mathrm{MH}$ and psychosocial support services in Syria and among Syrian refugees in neighboring countries found that levels of depression ranged from 11 to $49 \%$ (13). Similarly, another systematic review and meta-analysis recently estimated the prevalence of mental disorders at $21.1 \%$ in conflict-affected settings (14). However, mental healthcare in Syria has been neglected for decades (15), and studies on access and barriers to $\mathrm{MH}$ and psychosocial support in Syria are quite limited (13). It has been suggested that stigma associated with psychological and psychiatric disorders stands in the way of the use of MH services among Syrians in Syria $(16,17)$. Importantly, Syrians with a refugee background may seek help differently in Norway than Syria (17). This could relate to the different role of the GP in these countries. In Norway, patients, who want to see a specialist funded by the state are required to seek help via their GP (18). In Syria, however, patients are typically able to access specialist services directly, experiencing fewer delays and waiting times (17). Furthermore, the GP may be seen as a source of help for physical problems rather than $\mathrm{MH}$ problems. It is also worth noting that some services that are available in Norway, such as social workers, may not be a relevant source of help in Syria and may therefore not be considered.

Refugees' underuse of health services in high-income countries may, in part, be due to barriers to access and use. In Germany and Austria, Syrian refugees have identified barriers to help-seeking, such as stigma and shame, not speaking the language of the host country, and lacking information about health services (19-21). Similarly, refugees in Turkey have identified barriers such as not knowing where or how to get help, financial concerns, unavailability of appointments, fear of being hospitalized, and finding the process inconvenient or time-consuming (22). Such barriers may stand in the way of refugees accessing health care. The barriers perceived by Syrian refugees in a Norwegian context, however, have not been examined previously. The Norwegian public healthcare system is characterized by universal health coverage for all residents, although individuals make modest co-payments for different services. Services covered by universal health care include primary care, hospital care, and mental healthcare. Enrolment in universal healthcare is automatic, meaning that all residents have the right to state funded primary healthcare. Due to differences between countries' healthcare systems, we must assume that barriers perceived in other countries are not necessarily transferrable to the Norwegian context. Although it must be noted that refugees' expectations about the healthcare system in Norway may be influenced by their experiences in other countries.

Help-seeking is also influenced by factors besides barriers to accessing care. Andersen's behavioral model of health services use $(\mathrm{BM})(23,24)$ presents how contextual and individual factors, as well as health behaviors and outcomes, interact and influence the use of health care services (referred to as personal health services in the model). However, the experience of illness as well as preferences for seeking help are embedded in larger cultural and social systems (25). As an individual's cultural context changes, help-seeking preferences and behaviors are likely to change as well. This is supported by interviews with Syrian refugees (17). Similarly, preference for cultural traditions of the host country (including willingness to marry a Norwegian person, participating in social activities with Norwegians, etc.) was associated with semiformal (e.g., internet forum) and formal (i.e. medical doctor) as opposed to informal help-seeking sources among immigrants in Norway (26). This is in line with Wikberg and Eriksson (79), who claim that the more integrated an individual feels, the more likely they are to accept the host country's dominant care models. While previous studies have considered culture in relation to the BM (27), it may not suffice to include culture as a static variable, in the form of cultural values for example, without acknowledging the unique circumstances caused by shifting cultural contexts. This gap may be addressed by examining the concept of integration, defined as "the degree to which immigrants have the knowledge and capacity to build a successful, fulfilling life in the host society" $(28,29)$, in relation to help-seeking. Note, that the term "integration" does not imply that immigrants must surrender their own cultural identity and traditions to successfully integrate (30). Harder and colleagues (29) propose their multidimensional measure of immigrant integration spanning the domains of psychological, social, linguistic, economic, navigational, and political integration.

Harder's multidimensional measure of immigrant integration, or Immigration Policy Lab (IPL), can be used to measure integration overall or in its individual facets (linguistic, psychological, etc.), in contrast to several other measures, such as the Vancouver acculturation inventory (31) and the cultural competence scale (32-34) which examine similar facets, but combine these into an overall score. Furthermore, Harder's measure examines the current social situation of the participants, including amount of contact with members of the host society, while the Acculturation orientation scale (34) and Vancouver acculturation inventory (31) focus on individuals' preferences, including how important social contact with ingroups and outgroups is to participants. For the current 
study, we felt it was more helpful to employ a measure, which considers the participants' current situation rather than their preferences. Furthermore, as Harder et al. point out in the Supplementary Material of their paper, by "directly measuring the frequency of a social interaction, the question has face validity for measuring social integration" (29). Importantly, other scales assume that participants have friends in the resettlement country. Since this is not necessarily the case for all refugees, we have included single item measures to examine number of Norwegian and Syrian friends in Norway. Single item measures have been used previously to measure number of friends among refugee groups $(35,36)$. In a relatively hard to reach population, such as Syrian refugees in Norway, it is important that surveys remain short and concise. Harder's measure captures "key aspects of integration with a small number of widely applicable questions" and "can be used at low cost and facilitate comparability" (p. 11484). Their measure can therefore be used as a "common measure of integration, which would allow for the accumulation of knowledge through comparison across studies, countries, and time" [(29), p. 11483]. Harder's measure has furthermore been validated among relevant populations, including refugees as well as immigrants both in Europe and the United States (29).

The important role of integration in other domains besides help-seeking has been described previously, which lends support to the potential importance of this concept in help-seeking. A lack of social integration, for example, may be associated with decreased health-related quality of life, functional impairment, and severity of depression symptoms, anxiety, and PTSD (37). Similarly, while the beneficial impact of inter-ethnic friendships on the integration and well-being of migrant youths $(38,39)$ and adults (40) has been supported in previous research, the role of friendships in migration research has been largely treated as a side issue (41). Research conducted in Germany has suggested that social capital may facilitate integration of Syrian refugees into the labor market, and that different types of social capital may affect the outcome of the integration process (although the presence of social capital does not invariably lead to the successful utilization of that capital) (42). The importance of social integration has also been addressed by the German Institute for Economic Research, who suggest that social integration is vital in improving refugees' trust in key state institutions (43). Consequently, we incorporate elements of Harder's integration measure (2018) into Andersen's BM $(2008 ; 2014)$ to guide the current study.

The present exploratory study focuses on the Norwegian context. While some specialist MH services exist for refugees, the majority that are officially settled in Norway are encouraged to contact their GP, who acts as a gatekeeper to specialist services (18). Like the rest of Europe, Syrian refugees in Norway have reported higher rates of $\mathrm{MH}$ problems. A recent cross-sectional study found that $33 \%$ of Syrian refugees in Norway reported symptoms indicative of anxiety or depression, and 7\% reported symptoms of post-traumatic stress disorder (PTSD) (44). These rates are substantially higher than the 12-month prevalence of $10-15 \%$ for anxiety or depression (45), and 1-1.7\% for PTSD (for men and women, respectively) among the Norwegian majority population (46). The aims of the current exploratory study are
[1] to describe how the GP fits into the larger context of helpseeking preferences among Syrian refugees in Norway, and what barriers participants identify to accessing help from the GP, [2] to examine how the likelihood of seeking help from the GP relates to indicators of integration as well as other social, psychological, and demographic variables guided by the BM.

Furthermore, we focus on the GP as a source of help and the individual characteristics presented in the behavioral model (BM) as factors that may impact willingness to seek help from the GP. It is likely that throughout an individuals' life span either they or someone close to them will experience symptoms of depression. As a result, laypeople's beliefs about seeking help for depression have important implications for the behavior of people suffering from depression.

According to the $\mathrm{BM}$, the personal characteristics that influence help-seeking include predisposing (demographic, social, beliefs), enabling (financial resources, organization), and need (perceived and evaluated) $(23,24)$. While predisposing and enabling factors are sometimes difficult to disentangle (47), a predisposing factor can be thought of as something that would influence a person's willingness to seek help, while an enabling factor would influence their ability to receive help. Based on previous literature that has used the BM, we include age, gender, relationship status $(47,48)$, and education $(48,49)$ as predisposing demographic factors. In addition, we include perceived benefit of seeking help from the GP under predisposing beliefs, as this taps into the attitudes, values, and knowledge about health and health services (24). Here, we also incorporate Harder's social integration index and number Syrian and Norwegian friends, because this maps onto the social predisposing factors described in the $\operatorname{BM}(23,24)$. We chose to include psychological integration under predisposing factors, as we felt it best related to beliefs about health and healthcare $(23,24)$, although it could also be argued that psychological integration can be seen as an enabling factor. We include Harder's economic integration index under enabling financing, similar to Johnson and colleagues (48). We examine lack of access to the GP under enabling characteristics, as it either facilitates or impedes health services use $(23,24)$, and does not predispose an individual to seek health help. We incorporate the indices for navigational and linguistic integration within a separate box entitled "Knowledge" within enabling factors, as these did not fit within another category of the model but have been shown to have important implications regarding help-seeking $(1,5,10)$. Navigational integration, referring to an individual's ability to manage basic needs in the host country, best matched the element "organization" in the BM, which includes the existence of, and ability to access, a regular source of care. Furthermore, language proficiency, which is closely related to linguistic integration, has previously been included as an enabling factor (50). Finally, we include perceived severity of the problem under perceived need, because it captures participants' own perception of the severity of the symptoms. Severity of depression has previously been shown to relate to help-seeking (49), although it is unclear whether this is the case when responding to a vignette. Evaluated need from the original model is excluded as participants were not evaluated by 


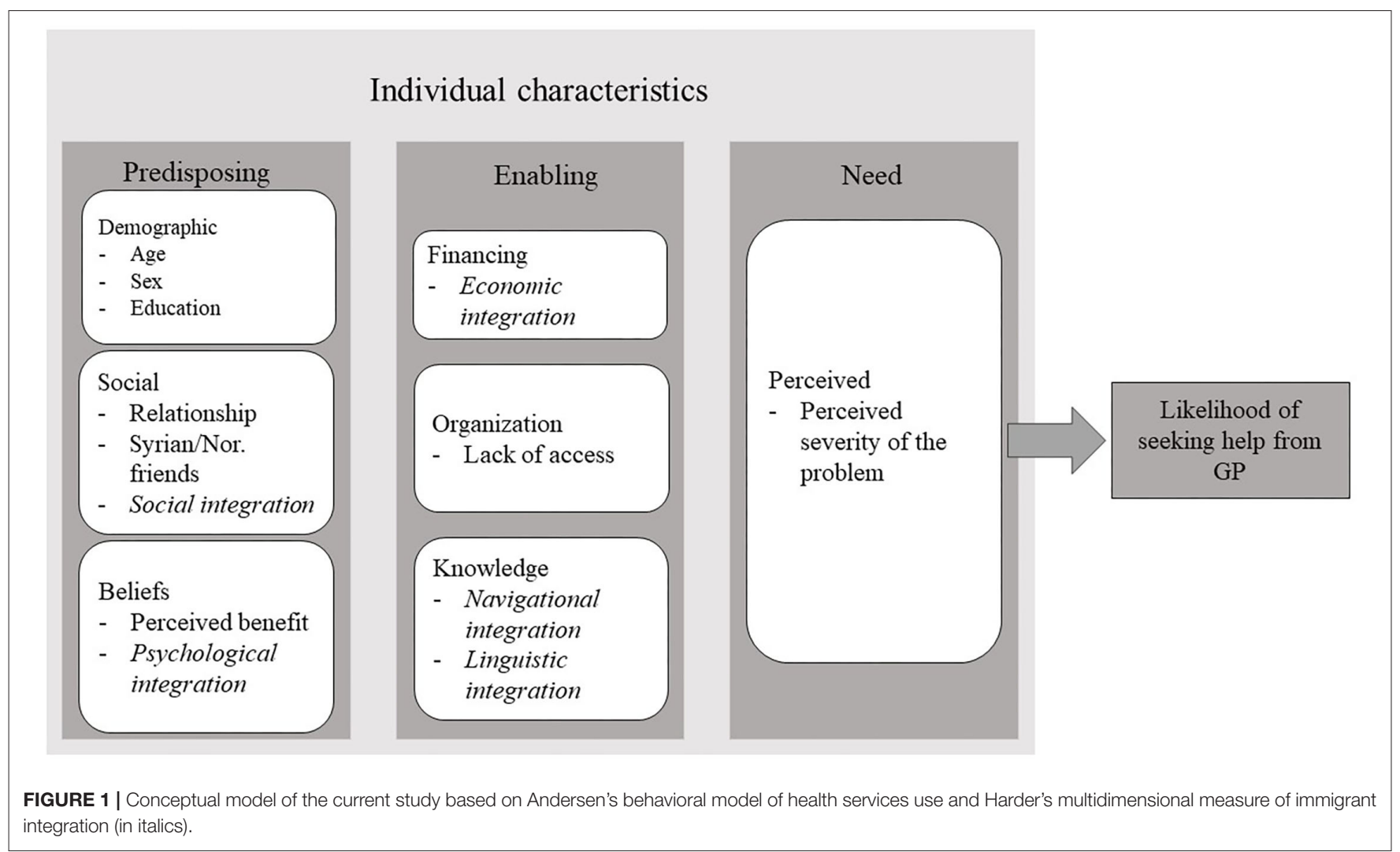

a health professional. Our adapted conceptual model is presented in Figure 1.

\section{MATERIALS AND METHODS}

\section{Participants and Procedure}

The current study was embedded in a larger survey study on refugees and $\mathrm{MH}$. Our target population were Syrian refugees over the age of 18 . We recruited participants through a purposive sampling strategy (51). Participants were mainly contacted through adult education programs ${ }^{1}$ in two large Norwegian cities. Most participants completed the survey onsite, either on their own mobile devices, or on an iPad provided by the researchers. Participants were also given the option to respond to a paper version of the questionnaire, and to complete the survey in Arabic or Norwegian. An Arabic speaking research assistant was available for support onsite. A link to the survey was furthermore advertised on the research group's official website and shared via personal and professional networks. Data were collected throughout 2019, and the final responses were collected on the 14th of February 2020. Recruitment of participants was planned to continue beyond this time frame but had to be

\footnotetext{
${ }^{1}$ The adult education programs are part of a broader service offered to migrants by the Norwegian authorities and provide training for individuals to qualify for further study or employment in Norway. This includes the introductory program, which is mandatory for refugees, as well as other courses to improve individuals' job and further education opportunities.
}

terminated due to the COVID-19 pandemic and the ensuing lock down.

A total of 478 participants opened the survey link. Participants who consented to take part $(N=275)(57.5 \%)$ were randomized to one of two survey versions after answering demographic questions. Sixty-eight participants consented but dropped out prior to randomization. Of those that were randomized, 101 were randomized to the current study on help-seeking. Despite stating that we were recruiting participants from Syria with a refugee background, 4 individuals born in Norway participated. These were excluded from the final analysis. Similarly, participants were excluded if they did not respond to the help-seeking questions ( $n$ $=5$ ), leaving a final sample of $n=92$. Among these, there were some missing datapoints, but 82 completed the entire survey.

The final sample included 55 men and 37 women. Participants' ages were collected in 10-year age brackets. Most participants were between 30 and 39 years old (35.9\%) followed by the 20-29 age group (37.0\%). According to data from Statistics Norway (personal correspondence, 2021), of the 32,168 Syrians that moved to Norway between 2000 and 2021, 78\% arrived as refugees and $22 \%$ arrived as family reunification cases. A vast majority of these individuals immigrated in 2015 and 2016. Consistent with this, we found that most of our participants indicated that their age of arrival corresponded to their present age group $(58.7 \%)$ followed by having moved one age bracket up since arrival (39.1\%). This suggests that our sample comprises recently settled refugees, in line with the pattern of immigration to Norway from Syria (52). Based on our sample size, (given $\alpha$ 
$=0.05$, two-tailed), we had a power of 0.80 to detect a medium effect size of $r=0.31$, a power of 0.99 to detect a medium to large effect of $r=0.45$, and a power of 0.15 to detect a small effect size of $r=0.11$ (53).

A minority of respondents reported being employed (21.7\%), and most lived in a household with very low $(33.7 \%)$ or extremely low (25.5\%) annual incomes. The educational level of the respondents varied; many were educated at university/college level (51.1\%), and about equal proportions of respondents indicated high school $(14.1 \%)$ or elementary school $(21.7 \%)$ as their highest completed level of education. Most of our sample were in a relationship (married or cohabiting) $(64.1 \%$ ) and about half (46.7\%) had children. Participants' demographic characteristics are presented in Supplementary Table 1 in the Supplementary Material.

Given the high prevalence of depressive symptoms and related $\mathrm{MH}$ problems in refugee populations, it is likely that some of our participants experienced depressive symptoms at the time of the survey. We included common psychiatric disorders, general selfrated health, and identification with the vignette character in the current study to examine the relationship between these variables and what participants report they would do in case they felt like the vignette character.

\section{Measures}

\section{Help-Seeking}

To measure help-seeking preferences, participants were presented with a vignette describing an individual, who was experiencing symptoms in line with DSM-V and ICD-10 criteria of depression $(54,55)$. The vignette is the same as used by Aarethun et al. (17), Markova et al. (56), and Markova et al. (26), which is based on Erdal and colleagues (57). Female participants were presented with a female vignette character and males with a male vignette character. The vignettes were otherwise identical (Supplementary Material 2).

After reading the vignette, participants indicated how likely they were to seek help from different sources, if they felt like the vignette character (6-point Likert scale where $1=$ Very unlikely, $6=$ Very likely, and $7=$ NA). Participants could select from a list of different sources, based on categories used by Markova et al. (26) and the General Help-seeking Questionnaire (58). Next, the participants were asked to indicate their first, second, and third most preferred help-seeking sources.

\section{Barriers to Seeking Help From the GP}

Based on barriers commonly mentioned in the literature (59-62) we developed a list of potential barriers for seeking help from the GP. Similar barriers have since been described in more recent studies $(1,63)$. The list of possible barriers is presented in the results section.

\section{Integration Indices}

We employed the integration indices as described in the Supplementary Material of Harder et al. (29). We followed the IPL-12 (Immigration Policy Lab-12) version of the measure for all indices apart from social and psychological integration, for which we included additional items from the IPL-24. Note that we excluded the index for political integration, as it had no clear link to help-seeking preferences.

\section{Social Integration}

The social integration index consisted of three items, such as "In the last 12 months, how often did you eat dinner with Norwegians who are not part of your family?" ( $1=$ Never, $5=$ Almost every day). The index had "acceptable" internal consistency $(\alpha=0.64)$ according to previous literature (64).

\section{Psychological Integration}

The psychological integration index consisted of four items, such as "How connected do you feel with Norway?" (5 = I feel an extremely close connection, $1=\mathrm{I}$ do not feel a connection at all). The index had good internal con sistency $(\alpha=0.83)$.

\section{Linguistic Integration}

Linguistic integration was measured by two items as follows: "Communicating in Norwegian has many components, like reading, writing, and speaking skills. Please evaluate your own skills in Norwegian": "I can read and understand the main points in simple newspaper articles on familiar subjects" and "In a conversation, I can speak about familiar topics and express personal opinions" ( $5=$ Very well, $1=$ Not well at all) $(r=0.83)$.

\section{Navigational Integration}

We initially based navigational integration on the two items included in the IPL-12 (29): "In this country, how difficult or easy would it be for you to do each of the following? (A) See a doctor. (B) Search for a job (find proper listings)" (1 = Very difficult, $5=$ Very easy). However, the items were uncorrelated in our sample $(r=0.07)$. Therefore, we employ only the single item regarding finding a doctor, which was most relevant to the scope of this paper.

\section{Economic Integration}

The economic integration index used in the current study consists of one item examining household income equalized by household size. Originally, this item is to be combined with occupational status, but these two items were uncorrelated in our sample $(r=0.09)$, and we thus focus on equalized household income only.

\section{Number of Norwegian and Syrian Friends}

Number of Norwegian and Syrian friends was examined through the items "Do you have one or more Norwegian friends" and "Do you have one or more Syrian friends?" ( $1=$ No, $2=$ Yes, I have one friend, 3 = Yes, I have several), which was dichotomized for the analysis ( $1=$ No, $2=$ Yes, I have one or several friends).

\section{Perceived Severity}

Perceived severity was measured by asking participants whether they felt the vignette character's condition was severe enough to warrant sick leave (Yes/No).

\section{Identification With the Vignette Character}

We measured identification with the vignette character by asking participants to what extent two progressively overlapping circles represent them and the vignette character. Circles A, for example, 
represented two separate circles (coded as 1 ), while circles $G$ were almost entirely overlapping (coded as 7).

\section{Self-Rated Health}

Participants' general self-reported health (GSRH) was measured through the single item: "Overall, would you say your health is:" with the response options ranging from (5) Excellent to (1) Very Poor. This question has previously been used to measure self-rated health among Syrian refugees migrating to Norway (65) and has been validated among Arabic speaking refugee populations (66).

\section{Common Mental Disorders}

Common mental disorders were measured using the HSCL-25 (67). Participants were asked to report to what extent a range of experiences applied to them over the last 14 days $(1=$ Not at all, $4=$ A lot). The Norwegian and Arabic translations of this survey have been validated in Norwegian and Arabic samples $(68,69)$. In our sample, mean HSCL score for men was $2.20(\mathrm{SD}=0.71)$ and $2.04(\mathrm{SD}=0.67)$ for women. Of these, $63 \%$ of women and $75 \%$ of men scored above the clinical cut-off of $1.75(70)$. While we are cautious to determine an optimal clinical cut-off in the current sample, it appears that a substantial number of participants reported symptoms indicative of psychological distress.

\section{Ethical Considerations}

This study was approved by the Norwegian Center for Research Data (NSD Notification form: 602214). All participants gave written consent in accordance with the Declaration of Helsinki (71) at the start of the survey. Participation was voluntary, anonymous, and confidential.

\section{RESULTS}

\section{The GP as a Source of Help}

Participants' likelihood of seeking help from different sources is presented in Table 1. The GP ranked as the fourth most likely source of help, preceded by Allah/God, participants' partner, and mother. To further explore the likelihood of seeking help from the GP in comparison to other positively rated help-seeking sources, we conducted a series of paired samples Wilcoxon signed rank tests. Due to the number of tests and the exploratory nature of our analyses, we employed a more stringent alpha level of 0.01 . These tests revealed that the likelihood score of seeking help from the GP was significantly lower than that of seeking support from Allah/God $(T=5453.5, p<0.001)$ and one's partner $(T=2721.5$, $p=0.009$ ). However, we found no significant difference between the mean likelihood rating of seeking help from the GP and one's mother $(T=3578.5, p=0.530)$, a psychologist/psychiatrist $(T=$ $4132, p=0.811)$, other family members $(T=4209.5, p=0.460)$, Syrian friends $(T=4322.5, p=0.124)$, father $(T=3306, p=$ $0.279)$, the internet $(T=4870, p=0.011)$, or Norwegian friends $(T=4707, p=0.012)$. The likelihood score of seeking help from the GP was significantly higher than seeking help from a social worker $(T=5038.5, p \leq 0.001)$.

Figure 2 presents participants' top three help-seeking choices, based on the question "where would you seek help first,
TABLE 1 | Participants' likelihood of seeking help from different sources ordered by highest (top) to lowest (bottom) total mean likelihood score, standard deviation (SD), median, and interquartile range (IQR).

\begin{tabular}{|c|c|c|c|}
\hline & & Total & \\
\hline Help-seeking source & $N$ & Mean (SD) & Median (IQR) \\
\hline Allah/God & 86 & $5.13(1.56)$ & $6(5-6)$ \\
\hline Partner & 79 & $4.56(1.82)$ & $5(4-6)$ \\
\hline Mother & 85 & $4.05(1.94)$ & $5(2-6)$ \\
\hline GP & 89 & $3.98(1.76)$ & $4(2-6)$ \\
\hline Psychologist/Psychiatrist & 91 & $3.88(1.84)$ & $4(2-5)$ \\
\hline Other family member & 89 & $3.80(1.77)$ & $4(2-5)$ \\
\hline Syrian friends & 86 & $3.55(1.81)$ & $4(2-5)$ \\
\hline Father & 82 & $3.54(2.09)$ & $4(1-6)$ \\
\hline Internet & 90 & $3.33(1.68)$ & $4(2-5)$ \\
\hline Norwegian friends & 87 & $3.30(1.74)$ & $4(2-5)$ \\
\hline Social worker/NAV & 89 & $3.08(1.80)$ & $3(1-5)$ \\
\hline Nurse & 91 & $3.01(1.64)$ & $3(2-4)$ \\
\hline Physiotherapist & 86 & $2.85(1.73)$ & $2(1-5)$ \\
\hline Elders in my community & 88 & $2.84(1.60)$ & $3(1-4)$ \\
\hline None & 89 & $2.75(1.77)$ & $2(1-4)$ \\
\hline Colleague/someone at work & 90 & $2.74(1.65)$ & $2(1-4)$ \\
\hline Teacher/contact from introductory programme & 90 & $2.71(1.65)$ & $2(1-4)$ \\
\hline Telephone helpline & 81 & $2.53(1.56)$ & $2(1-4)$ \\
\hline A\&E & 88 & $2.52(1.67)$ & $2(1-4)$ \\
\hline Alternative treatment ${ }^{\star}$ & 85 & $2.42(1.68)$ & $2(1-4)$ \\
\hline Other & 82 & $2.39(1.71)$ & $2(1-3)$ \\
\hline Charity & 86 & $2.38(1.57)$ & $2(1-3)$ \\
\hline Religious leader (e.g., imam or priest) & 88 & $2.33(1.59)$ & $2(1-4)$ \\
\hline Traditional healer from my country of origin & 86 & $2.05(1.35)$ & $2(1-3)$ \\
\hline Leader from my community or country of origin & 86 & $1.81(1.12)$ & $1(1-2)$ \\
\hline
\end{tabular}

Responses were indicated on a 6-point Likert scale, where $1=$ very unlikely and $6=$ very likely, $7=N A$. Responses are based on a sample size of $N=92 . N$ in the table presents participants who chose a likelihood rating between 1 and 6. Not all sources of help may have been relevant for all participants. *Alternative treatment was specified as: e.g., acupuncture, homeopathy, herbal treatment.

second, or third." The most frequent first choices were partner, Allah/God, and mother. The most frequent second choices were mother, partner, and psychologist/psychiatrist followed closely by the GP. Finally, the third choices were spread more evenly, with the internet ranking as the most common third choice, followed closely by mother and none, which was chosen similarly as often as psychologist and other family member. Figure 2 extends the findings from the paired Wilcoxon rank tests and suggests that there is a preference for seeking help from Allah/God and one's partner over seeking help from one's GP.

\section{Barriers to Seeking Help From the GP}

Barriers to seeking help from the GP are presented in Figure 3. Of 92 participants, 87 identified at least 1 barrier. On average, participants reported 2 barriers $(S D=1.8)$. The most frequently chosen barriers were "language barriers," "I don't think it would help," "the waiting times are too long," and "I don't think my GP would understand". 


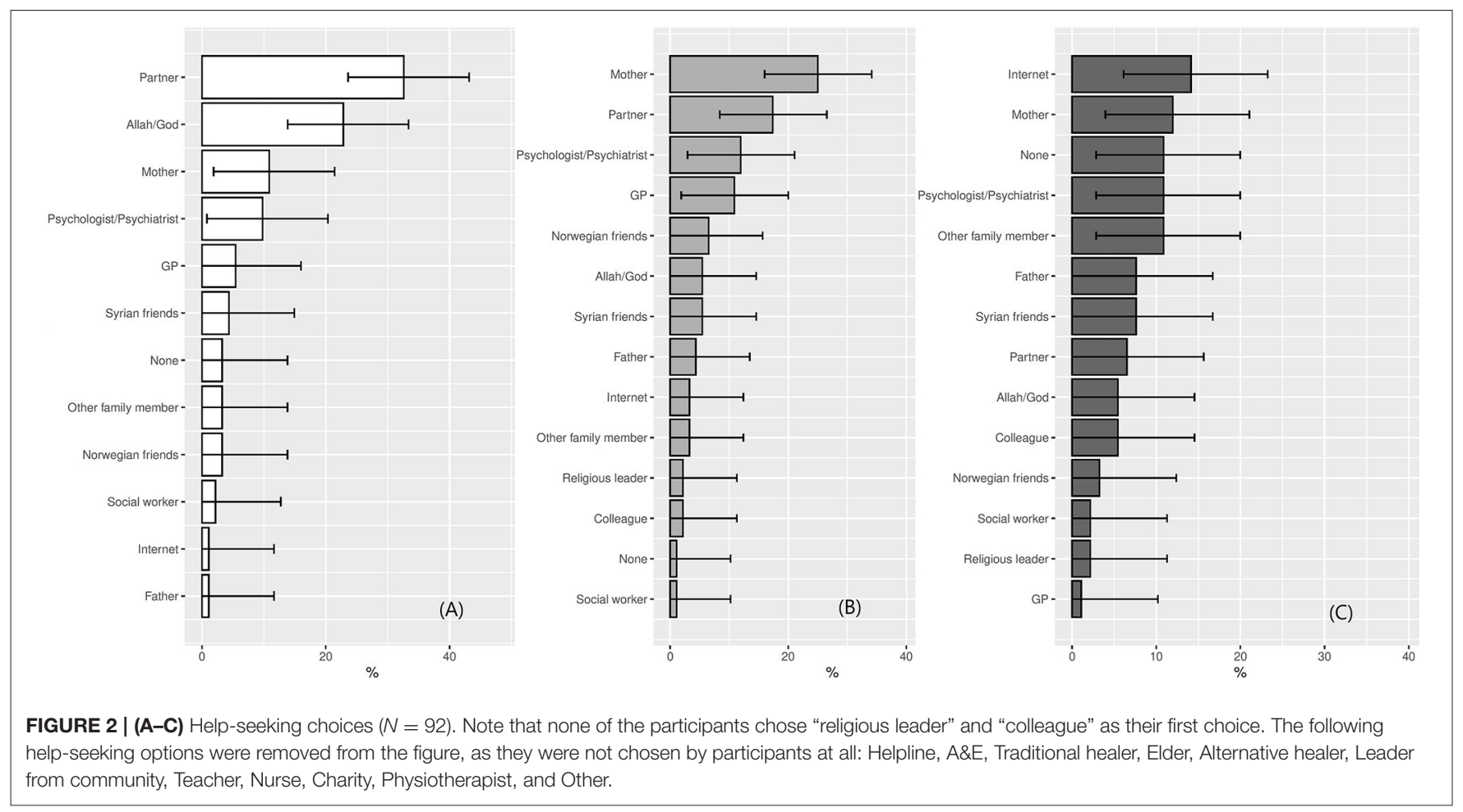

We created a measure of lack of perceived benefit by combining the barriers "I don't think it would help," "I don't think my GP would understand," and "I don't trust my GP." Lack of perceived benefit of seeking help from the GP was negatively correlated with likelihood of seeking help from the GP, $\left[r_{s}(87)\right.$ $=-0.35, p<0.001]$. We did not find, however, lack of access in the form of not having a GP, not knowing who the GP is or how to contact them, to be central barriers in our sample. The final element of access, waiting times-endorsed by 27 of 87 participants -, was positively correlated with seeking help from the GP $\left[r_{s}(87)=0.22, p=0.038\right]$. The fact that individuals had the experience of long waiting times suggests that they had access to their GP, and the positive correlation indicates that long waiting times did not systematically deter participants from considering the GP as a viable source of help. Given the emphasis placed on stigma and shame in previous research, it is notable that very few participants $(n=3)$ indicated that seeking help form the GP would be shameful.

\section{The Role of Integration in the Behavioral Model}

Our second aim was to examine several socio-demographic variables based on previous literature and their relation to endorsing seeking help from the GP, as well as address integration's role in the model. Correlations between all variables are presented in Table 2. In terms of socio-demographic variables, we found that neither gender nor education were related to endorsing help-seeking from the GP.

Higher psychological $\left[r_{s}(83)=0.24, p=0.028\right]$ and social integration $\left[r_{s}(81)=0.32, p=0.003\right]$ were both positively correlated with likelihood of seeking help from the GP. We did not find any significant associations between having Norwegian friends, Syrian friends, economic, linguistic, or navigational integration and reported likelihood of seeking help from the GP. It is worth noting, however, that while there was no significant correlation between number of Norwegian friends and likelihood of seeking help from the GP, both psychological and social integration were significantly correlated with Norwegian friends (see Table 2), suggesting that the effect of Norwegian friends may be indirect.

\section{Perceptions of Severity and Participants' Own Health Status}

Neither perceived severity of the condition $\left[r_{s}(87)=-0.02, p\right.$ $=0.875]$, participants' own self-reported health status $\left[r_{s}(83)\right.$ $=-0.15, p=0.157]$, mean HSCL score $\left[r_{s}(81)=-0.03, p=\right.$ $0.818]$, nor their identification with the vignette character $\left[r_{s}(86)\right.$ $=-0.05, p=0.651]$ was correlated with endorsing seeking help from the GP. While we did not include these variables in the conceptual model, these results suggest that individuals are not influenced by their current health status when considering potential sources of help for the future. Furthermore, these variables act as validity checks, in that HSCL score is correlated with identification with the vignette character $[r(84)=0.57, p<$ $0.001]$, as well as self-reported health $[r(84)=-0.52, p<0.001]$.

\section{DISCUSSION}

\section{Summary of Results}

The findings of the current exploratory study suggest that Syrians with a refugee background considered seeking help from the GP as somewhat likely if they experienced symptoms 


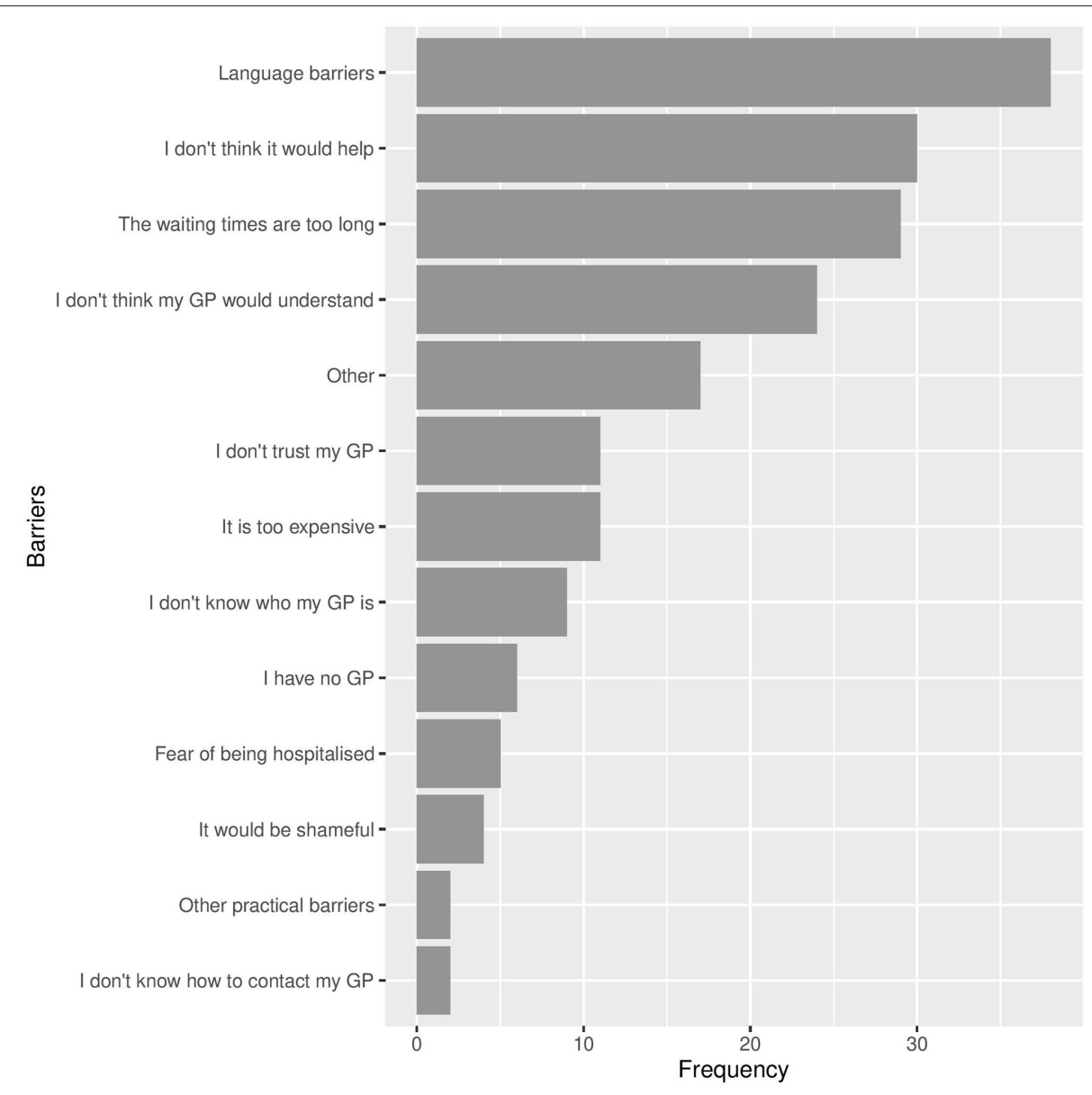

FIGURE 3 | Barriers reported by participants to seeking help from the GP $(N=87)$. Note that participants could select several or no barriers.

in line with depression. Formal sources of help, such as the GP and psychologist/psychiatrist, were preceded by Allah/God and one's partner as preferred sources of help. Furthermore, participants indicated experiencing an average of two barriers to seeking help from the GP. The most prevalent barriers included language barriers, not thinking it would help, long waiting times, and feeling like the GP would not understand. We found that psychological and social integration, i.e., feelings of connectedness with Norway and having a Norwegian social network, were correlated with higher reported likelihood of endorsing the GP as a viable source of help.

\section{Previous Literature and Implications The Role of the GP as a Source of Help}

Our findings suggest that Syrians with a refugee background in the current sample preferred to seek help from Allah/God and their partner over the GP or psychologist/psychiatrist, but that the GP and psychologist/psychiatrist were nevertheless considered viable help-seeking sources. This has been found among Syrian refugees in Istanbul, who reported a preference for seeking help from informal sources, such as family, but also endorsed seeking help from professional sources (22).
Participants in the latter sample also reported religious leaders as a common source of help (22), while our sample ranked religious leaders as very unlikely help-seeking sources and Allah/God as a very likely source of help. Our findings, therefore, suggest there may be an important difference between turning to one's relationship with Allah/God for help and seeking help from religious leaders. We must also consider that some sources of help, such as social workers, may not be relevant in Syria, which may explain why participants considered social workers as a relatively unlikely source of help in the current study. Nevertheless, all refugees receive information about $\mathrm{MH}$ and formal help-seeking sources as part of the introductory program, which would have raised awareness about social workers and their role in Norwegian society.

It is important to remember that help-seeking sources are not mutually exclusive (5), and individuals may consider seeking help from both formal as well as informal sources simultaneously. Adopting both dominant care models as well as the care models of the home country has the advantage of affording individuals more options (72). However, Atallah (72) draws particular attention to the conflict that may arise when the dominant care 
TABLE 2 | Spearman's rank (in gray) and pearson correlations among study variables.

\begin{tabular}{|c|c|c|c|c|c|c|c|c|c|c|c|c|c|c|c|c|}
\hline & 1. & 2. & 3. & 4. & 5. & 6. & 7. & 8. & 9. & 10. & 11. & 12. & 13. & 14. & 15. & 16. \\
\hline 1. Seeking help from GP & - & & & & & & & & & & & & & & & \\
\hline 2. Gender & -0.02 & - & & & & & & & & & & & & & & \\
\hline 3. Age & $0.27^{*}$ & -0.16 & - & & & & & & & & & & & & & \\
\hline 4. Education & 0.05 & -0.10 & 0.03 & - & & & & & & & & & & & & \\
\hline 5. Relationship & $-0.26^{\star}$ & -0.17 & 0.01 & 0.01 & - & & & & & & & & & & & \\
\hline 6. Syrian friends & 0.11 & -0.05 & -0.04 & 0.13 & -0.03 & - & & & & & & & & & & \\
\hline 7. Norwegian friends & 0.09 & 0.03 & $0.23^{\star}$ & -0.04 & $-0.25^{\star}$ & 0.07 & - & & & & & & & & & \\
\hline 8. Lack of benefit & $-0.35^{\star}$ & -0.06 & -0.17 & 0.07 & 0.02 & -0.06 & -0.19 & - & & & & & & & & \\
\hline 9. Severity & -0.02 & 0.18 & 0.00 & 0.00 & -0.10 & 0.10 & 0.10 & -0.15 & - & & & & & & & \\
\hline 10. Vignette character identification & -0.05 & 0.04 & -0.16 & $-0.23^{\star}$ & 0.13 & 0.00 & -0.09 & 0.04 & -0.08 & - & & & & & & \\
\hline 11. Health & -0.15 & 0.01 & -0.15 & 0.05 & -0.11 & -0.02 & $0.27^{\star}$ & -0.06 & 0.19 & $-0.34^{\star}$ & - & & & & & \\
\hline 12. HSCL & -0.03 & -0.11 & -0.16 & 0.03 & 0.16 & 0.00 & $-0.25^{\star}$ & $0.30^{*}$ & -0.16 & $0.57^{\star \star}$ & $-0.51^{\star \star}$ & - & & & & \\
\hline 13. Social integration & $0.32^{\star \star}$ & -0.10 & $0.28^{*}$ & 0.03 & $-0.23^{\star}$ & 0.13 & $0.56^{\star \star}$ & ${ }^{*}-0.20$ & 0.06 & -0.08 & 0.20 & -0.15 & - & & & \\
\hline 14. Psychological integration & $0.24^{*}$ & 0.05 & 0.12 & -0.21 & -0.15 & $-0.22^{\star}$ & $0.27^{\star}$ & -0.20 & -0.02 & -0.18 & $0.26^{*}$ & $-0.35^{\star}$ & $0.34^{*}$ & - & & \\
\hline 15. Linguistic integration & -0.07 & -0.16 & -0.06 & $0.28^{\star}$ & -0.05 & 0.01 & 0.07 & 0.19 & -0.06 & -0.01 & -0.06 & 0.06 & 0.12 & -0.09 & - & \\
\hline 16. Economic integration & -0.06 & -0.14 & 0.01 & 0.19 & 0.00 & -0.03 & -0.01 & 0.01 & -0.07 & 0.04 & -0.09 & 0.10 & 0.10 & 0.07 & $0.27^{*}$ & - \\
\hline 17. Navigational integration & 0.07 & -0.16 & 0.04 & 0.06 & 0.00 & -0.10 & 0.10 & -0.18 & 0.14 & $-0.25^{\star}$ & $0.28^{*}$ & $-0.30^{\star}$ & 0.01 & 0.21 & 0.18 & 0.05 \\
\hline
\end{tabular}

Note. Gender (1 = male, $2=$ female), Relationship $\left(1=\right.$ Yes, $2=$ No), Syrian/Norwegian friends $\left(1=\right.$ No, $2=$ Yes, I have one or several). ${ }^{*} p<0.05$, ${ }^{* *} p<0.01$.

model of the patient's home and host country do not align. The current study finds no evidence for a conflict on the side of the participants, but we must acknowledge that a conflict may exist on the side of the practitioner. Practitioners in Norway are not expected to consider or recommend religious coping, despite evidence that religious coping has a range of benefits for mental well-being (73).

\section{Barriers to Seeking Help}

Commonly identified barriers to help-seeking, like language and waiting times (19-22), are in line with our results. Our findings also mirror reports from GPs working with refugee patients with $\mathrm{MH}$ problems (74). Language barriers in particular have been identified by GPs as obstacles to providing mental healthcare to refugees (74). Similarly, GPs have reported feeling as though refugee patients had different understandings of what constitutes and causes health and illness, resulting in a lack of understanding one another (74). The barrier "I don't think my GP would understand" chosen by participants in the current study mirrors this experience and suggests that language barriers as well as different understandings of health and illness may be perceived by both patients with a refugee background and their GPs.

Lack of perceived benefit was also indicated as an important barrier by our sample. Perceived benefit has previously been identified as one of the most important predictors of help-seeking intentions among adolescents (75). High perceived benefit may lead other barriers to become less important, and if confirmed in future research, may suggest that health promotion programmes, which focus on removing barriers should also promote the benefits of seeking help for MH problems (75).

However, other common barriers identified previously, such as stigma, shame, not knowing how to contact the GP, financial concerns, and fear of being hospitalized were not mirrored in our findings (19-22). With regards to shame and stigma, focus group interviews with Syrian refugees in Norway suggest that while stigma and shame influenced where individuals might seek help, they also acknowledged that stigma surrounding professional healthcare was diminished in Norway, making it easier and less stigmatized to seek professional MH help (17).

Finally, our findings suggest that current health status is not associated with considering the GP as a source of help; however, our findings do suggest that current health status is associated with other forms of help-seeking behavior ${ }^{2}$. This is in line with previous literature, which suggests that severity and duration of depression as well as chronic somatic disorders are related to help-seeking behaviors (49).

\section{Role of Social Networks and Feelings of Connectedness}

Intergroup contact and feelings of connectedness with the host country have previously been found to relate to well-being among refugees $(37,76)$. Less attention has been paid to psychological integration. Our results extend previous findings and address this gap in the literature, suggesting that social ties and feelings of connectedness, measured through the social and psychological integration indices (29), play an important role in considering seeking $\mathrm{MH}$ help from the GP. This further ties in with the importance of social capital, which has been shown to play a role in other domains, such as gaining access to the job market (42). Gericke et al. (42) distinguish between different types of social capital: bridging, referring to social contact with individuals outside of your community, vs. bonding social capital, marked by closed-off communities. They suggest that bonding social

\footnotetext{
${ }^{2}$ Additional analyses suggest that mean HSCL score was negatively correlated with seeking help from, for example, one's partner and mother.
} 
capital may put individuals at a disadvantage regarding accessing career-related information and social mobility. Furthermore, the authors highlight the difference between horizontal social capital, between people with similar access to resources and knowledge, and vertical social capital, which describes contacts who belong to different social levels (42). By the same virtue, Syrians with a refugee background in the context of the current study may benefit from having close ties to the Norwegian majority population, i.e., vertical, bridging social capital, with regard to the help-seeking sources they consider, and, consequently, are afforded more options regarding where to seek help. However, it is important to note that our sample had little variation regarding financial and employment situation. Consequently, our findings suggest that within an economically relatively deprived sample, social, and psychological integration play an important role in participants' consideration of professional sources of help, and do not necessarily imply that economic, navigational, or linguistic integration are not also important factors.

\section{Strengths and Limitations}

This study makes an important contribution by recognizing that help-seeking preferences are dynamic and contingent on time and context, rather a static characteristic. Similarly, much of the previous literature has framed help-seeking among refugee and non-refugee migrants in terms of barriers and factors that put them at a disadvantage to majority populations. While we also present barriers, our findings highlight social ties and feelings of connectedness as facilitators to help-seeking. Having collected data from Syrian refugees, our findings are particularly relevant to this patient group. Refugees are a highly heterogeneous group and "lumping them together" is neither appropriate nor informative (77). However, it should be noted that by the same token our findings may be less relevant for other patient groups. This may also be the case for important intragroup heterogeneity. For example, we did not consider ethnic identification within this participant group. Disregarding the differential culture of Kurds, for example, can gloss over important cultural differences that may play a role in help-seeking. Next, given the cultural differences presumed to exist with regard to our understandings of mental illness (5), we chose to present a vignette, which did not mention the term depression but instead described only the symptoms. This allowed us to gain an insight into individuals' help-seeking preferences for such symptoms without entangling our study in a larger discussion around the cross-cultural validity of "Western" nosology. The use of this vignette furthermore allowed Aarethun et al. (17) findings to complement the findings of the current study.

The study also had certain limitations that suggest caution should be exercised when interpreting the findings. We examined help-seeking preferences of Syrians with a refugee background regarding a fictional vignette character, which may not reflect participants' true help-seeking behaviors. Nevertheless, the preferences indicated in the current study may present what individuals are likely to endorse in situations where family and friends seek advice from them. Given the importance of certain informal help-seeking sources among this sample, this information is highly relevant. It is also important to note that help-seeking may differ by migrant background. Quota refugees and family reunification refugees in Norway are screened by a doctor, where many cases of $\mathrm{MH}$ problems are identified and managed. We chose not to collect information regarding specific reasons for arrival, as we felt this was too intrusive. However, if participants were to a large extent quota or family reunification refugees, it is possible that many are familiar with the Norwegian healthcare system. This may have impacted their willingness to consider the GP as a viable source of help, and therefore influenced our results. Similarly, we did not collect specific data regarding time spent in Norway, which has been shown to be an important variable regarding help-seeking in previous literature (1). Time spent in the host country is often employed as a proxy for integration or acculturation. The use of proxies, however, may be imprecise and implies that integration and other relevant processes progress similarly for all migrants over time. Our study improves this approach by examining integration directly. It is, however, important to note that we employed several single item measures. Both navigational and economic integration were intended to be measured through several items, but due to a lack of correlation between items we reduced these to single measure items. This is sample specific and should be corrected in future research. Finally, the social integration measure had a lower than desired reliability in the current sample. Nevertheless, the measure correlated meaningfully with other variables, such as seeking help from the GP, Norwegian friends and psychological integration, which may act as a form of validity check.

\section{Conclusion}

Our findings suggest that participants in the current study consider some formal help-seeking sources, such as the GP and psychologist/psychiatrist, for symptoms of depression. However, our findings also suggest that certain informal sources, such as one's partner and Allah/God, may be preferred. Given that help-seeking sources are not mutually exclusive, it is likely that individuals would seek help, or advise someone else to seek help, from a combination of both formal and informal help-seeking sources. However, most participants indicated an average of two barriers to seeking help from the GP. These included, for example, language barriers as well as feeling that the GP would not be able to help. This suggests important areas for interventions and future study. Our study also shows that social ties with the majority population as well as feelings of connectedness with the host country are correlated with considering seeking MH support from the GP. The current study thereby contributes to our understanding of help seeking as dynamic and contingent on cultural context. In line with calls for more non-confirmatory research, which may facilitate making hypothesis tests more informative (78), we encourage the use of our findings as inspiration and basis for future hypotheses. Measures of integration, particularly social and psychological integration, which acknowledge the consequences of shifting cultural contexts, should be considered in future research. Furthermore, future studies should consider longitudinal designs to examine the development of help-seeking preferences, and/or behaviors, over time. Future studies should also consider gender 
differences in help-seeking. Finally, given our focus on Syrians with a refugee background and a vignette displaying depression symptoms, future research ought to examine a variety of migrant groups as well as employ vignettes with different mental disorders.

\section{DATA AVAILABILITY STATEMENT}

The raw data supporting the conclusions of this article will be made available by the authors, without undue reservation.

\section{ETHICS STATEMENT}

The studies involving human participants were reviewed and approved by the Norwegian Center for Research Data. The patients/participants provided their written informed consent to participate in this study.

\section{AUTHOR CONTRIBUTIONS}

SH contributed to the conceptualization of the study, development of the methodology, conducted the formal analysis, wrote the initial draft, visualization of the findings, and writing- reviewing and editing subsequent drafts. GS contributed to supervision, conceptualization of the study, investigation and data collection, writing- reviewing and editing the manuscript, and acquired funding. HB contributed to the conceptualization of the study, the development of methodology, conducted the formal analysis, investigation and data collection, and writing- reviewing and editing the manuscript. P-EB contributed

\section{REFERENCES}

1. Satinsky E, Fuhr DC, Woodward A, Sondorp E, Roberts B. Mental health care utilisation and access among refugees and asylum seekers in Europe: a systematic review. Health Policy. (2019) 123:851-63. doi: 10.1016/j.healthpol.2019.02.007

2. WHO. Integrating Mental Health Into Primary Care - A Global Perspective. World Health Organization and World Organization of Family Doctors (2008).

3. Lu J, Jamani S, Benjamen J, Agbata E, Magwood O, Pottie K. Global mental health and services for migrants in primary care settings in high-income countries: a scoping review. Int J Environ Res Public Health. (2020) 17:8627. doi: 10.3390/ijerph17228627

4. Miller KE, Rasmussen A. War exposure, daily stressors, and mental health in conflict and post-conflict settings: bridging the divide between trauma-focused and psychosocial frameworks. Soc Sci Med. (2010) 70:7-16. doi: 10.1016/j.socscimed.2009.09.029

5. Kirmayer LJ, Narasiah L, Munoz M, Rashid M, Ryder AG, Guzder J, et al. Common mental health problems in immigrants and refugees: general approach in primary care. Canad Med Assoc J. (2011) 183:E959-67. doi: $10.1503 / \mathrm{cmaj} .090292$

6. Sijbrandij M, Acarturk C, Bird M, Bryant RA, Burchert S, Carswell $\mathrm{K}$, et al. Strengthening mental health care systems for Syrian refugees in Europe and the Middle East: integrating scalable psychological interventions in eight countries. Europ J Psychotraumatol. (2017) 8:1388102. doi: 10.1080/20008198.2017.1388102

7. De Jong J, Komproe IH, Van Ommeren M. Common mental disorders in postconflict settings. Lancet. to supervision, conceptualization of the study, and writingreviewing and editing the manuscript. LP contributed to the conceptualization of the study and writing- reviewing and editing the manuscript. All authors contributed to the article and approved the submitted version.

\section{FUNDING}

This project was funded by the Norwegian Research Council (Project Number: 273645).

\section{ACKNOWLEDGMENTS}

We would first like to thank all the contact persons who helped with the development of the survey and facilitated data collection. Special thanks to Dr. Samar Issa Albarghouthi and Dr. Ali Watti for drawing on their personal and professional experiences to support both the design and implementation of the survey. Thanks also to our reference group and colleagues from the Society and Workplace Diversity group for their invaluable feedback and support throughout this process. Last, but certainly not least, thanks to our hard-working research assistants (both former and current) Tuva Emilie Øyslebø, Kristin Skjærseth, Iphigenia Hellen, and Jaleb Clovis Nugame.

\section{SUPPLEMENTARY MATERIAL}

The Supplementary Material for this article can be found online at: https://www.frontiersin.org/articles/10.3389/fpubh. 2021.777582/full\#supplementary-material
(2003)

3692-6

8. Fazel M, Wheeler J, Danesh J. Prevalence of serious mental disorder in 7000 refugees resettled in western countries: a systematic review. Lancet. (2005) 365:1309-14. doi: 10.1016/S0140-6736(05)61027-6

9. Steel Z, Chey T, Silove D, Marnane C, Bryant RA, Van Ommeren M. Association of torture and other potentially traumatic events with mental health outcomes among populations exposed to mass conflict and displacement a systematic review and meta-analysis. JAMA. (2009) 302:53749. doi: 10.1001/jama.2009.1132

10. Hassan G, Ventevogel P, Jefee-Bahloul H, Barkil-Oteo A, Kirmayer LJ. Mental health and psychosocial wellbeing of Syrians affected by armed conflict. Epidemiol Psychiatric Sci. (2016) 25:129-41. doi: 10.1017/S2045796016000044

11. Ben Farhat J, Blanchet K, Bjertrup PJ, Veizis A, Perrin C, Coulborn RM, et al. Syrian refugees in Greece: experience with violence, mental health status, and access to information during the journey and while in Greece. BMC Med. (2018) 16:40. doi: 10.1186/s12916-018-1028-4

12. Poole DN, Hedt-Gauthier B, Liao S, Raymond NA, Barnighausen T. Major depressive disorder prevalence and risk factors among Syrian asylum seekers in Greece. BMC Public Health. (2018) 18:908. doi: 10.1186/s12889-0185822-x

13. Hendrickx M, Woodward A, Fuhr DC, Sondorp E, Roberts B. The burden of mental disorders and access to mental health and psychosocial support services in Syria and among Syrian refugees in neighboring countries: a systematic review. J Public Health. (2020) 42:E299-310. doi: 10.1093/pubmed/fdz097

14. Charlson F, Van Ommeren M, Flaxman A, Cornett J, Whiteford H, Saxena S. New WHO prevalence estimates of mental disorders in conflict 
settings: a systematic review and meta-analysis. Lancet. (2019) 394:240-8. doi: 10.1016/S0140-6736(19)30934-1

15. Kakaje A, Al Zohbi R, Aldeen OH, Makki L, Alyoubashi A, Alhaffar MBA. Mental disorder and PTSD in Syria during wartime - a nationwide crisis. BMC Psychiatry. (2021) 21:2. doi: 10.1186/s12888-020-03002-3

16. Hassan G, Kirmayer LJ A, M.-B., Quosh C, El Chammay R, et al. Culture, Context and the Mental Health and Psychosocial Wellbeing of Syrians: A Review for Mental Health and Psychosocial Support staff working with Syrians Affected by Armed Conflict. Geneva: UNHCR (2015) 1-52. Available online at: https://www.unhcr.org/protection/health/55f6b 90 f9/culture-contextmental-health-psychosocial-wellbeing-syrians-review-mental.html

17. Aarethun V, Sandal GM, Guribye E, Markova V, Bye HH. (2021). Explanatory models and help seeking for symptoms of PTSD and depression among Syrian refugees. Social Science \& Medicine 277. doi: 10.1016/j.socscimed.2021.113889

18. Helsenorge.No. Psychologist in Norway. (2019). Available online at: https:// www.helsenorge.no/en/psykisk-helse/psychologist-in-norway/

19. Kohlenberger J, Buber-Ennser I, Rengs B, Leitner S, Landesmann M. Barriers to health care access and service utilization of refugees in Austria: evidence from a cross-sectional survey. Health Policy. (2019) 123:833-9. doi: 10.1016/j.healthpol.2019.01.014

20. Renner A, Hoffmann R, Nagl M, Roehr S, Jung F, Grochtdreis T, et al. Syrian refugees in Germany: perspectives on mental health and coping strategies. $J$ Psychosomatic Res. (2020) 129:110415. doi: 10.1016/j.jpsychores.2019.109906

21. Zehetmair C, Zeyher V, Cranz A, Ditzen B, Herpertz SC, Kohl RM, et al. A walk-in clinic for newly arrived mentally burdened refugees: the patient perspective. Int J Environ Res Public Health. (2021) 18:2275. doi: 10.3390/ijerph18052275

22. Fuhr DC, Acarturk C, Mcgrath M, Ilkkursun Z, Sondorp E, Sijbrandij M, et al. Treatment gap and mental health service use among Syrian refugees in Sultanbeyli, Istanbul: a cross-sectional study. Epidemiol Psychiatric Sci. (2020) 29:e70. doi: 10.1017/S2045796019000660

23. Andersen RM. National health surveys and the Behavioral Model of Health Services Use. Medical Care. (2008) 46:647-53. doi: 10.1097/MLR.0b013e31817a835d

24. Andersen RM, Davidson PL, Baumeister SE. Improving access to care. In: Kominsky GF, editor. Changing the U. S. Health Care System : Key Issues in Health Services Policy and Management, 4 ed (San Francisco, CA: Jossey Bass) (2014) 24:33-69.

25. Kirmayer LJ, Rousseau C, Jarvis GE, Guzder J. The cultural context of clinical assessment. In: Tasman A, Kay J, Lieberman M, First M, Riba M, editors. Psychiatry. 4 ed. New York, NY: John Wiley \& Sons) (2015). p. 56-70. doi: 10.1002/9781118753378.ch4

26. Markova V, Sandal GM, Pallesen S. Immigration, acculturation, and preferred help-seeking sources for depression: comparison of five ethnic groups. BMC Health Serv Res. (2020) 20:648. doi: 10.1186/s12913-020-05478-x

27. Guo SS, Nguyen H, Weiss B, Ngo VK, Lau AS. Linkages between mental health need and help-seeking behavior among adolescents: moderating role of ethnicity and cultural values. J Counsel Psychol. (2015) 62:682-93. doi: $10.1037 /$ cou0000094

28. Kymlicka W. Multicultural Citizenship: A Liberal Theory of Minority Rights. Oxford: Clarendon Press (1995). doi: 10.1093/0198290918.001.0001

29. Harder N, Figueroa L, Gillum RM, Hangartner D, Laitin DD, Hainmueller J. Multidimensional measure of immigrant integration. Proc Natl Acad Sci USA. (2018) 115:11483-11488. doi: 10.1073/pnas.1808793115

30. Berry JW. A psychology of immigration. J Soc Issues. (2001) 57:615-31. doi: 10.1111/0022-4537.00231

31. Ryder AG, Alden LE, Paulhus DL. Is acculturation unidimensional or bidimensional? A head-to-head comparison in the prediction of personality, self-identity, and adjustment. J Personal Soc Psychol. (2000) 79:49-65. doi: 10.1037/0022-3514.79.1.49

32. Lay C, Nguyen T. The role of acculturation-related and acculturation non-specific daily hassles: vietnamese-Canadian students and psychological distress. Canadi J Behav Sci Revue Canad Des Sci Du Comportement. (1998) 30:172-81. doi: 10.1037/h0087060

33. Safdar S, Lay C, Struthers W. The process of acculturation and basic goals: testing a multidimensional individual difference acculturation model with Iranian immigrants in Canada. Appl Psychol Int Rev Psychol Appliquee-Revue Internationale. (2003) 52:555-79. doi: 10.1111/1464-0597.00151
34. Safdar S, Ray-Yol E, Reif JAM, Berger R. Multidimensional Individual Difference Acculturation (MIDA) model - Syrian refugees' adaptation into Germany. Int J Intercultural Relat. (2021) 85:156-69. doi: 10.1016/j.ijintrel.2021.09.012

35. Hynie M, Mcgrath S, Bridekirk J, Oda A, Ives N, Hyndman J, et al. What role does type of sponsorship play in early integration outcomes? Syrian refugees resettled in six Canadian cities. Refuge. (2019) 35:36-52. doi: 10.7202/1064818ar

36. Ahmad F, Othman N, Hynie M, Bayoumi AM, Oda A, Mckenzie K. Depression-level symptoms among Syrian refugees: findings from a Canadian longitudinal study. J Mental Health. (2021) 30:246-54. doi: 10.1080/09638237.2020.1765998

37. Schick M, Zumwald A, Knopfli B, Nickerson A, Bryant RA, Schnyder U, et al. Challenging future, challenging past: the relationship of social integration and psychological impairment in traumatized refugees. Europ J Psychotraumatol. (2016) 7:28057. doi: 10.3402/ejpt.v7.28057

38. Windzio M. Immigrant children and their parents: is there an intergenerational interdependence of integration into social networks? Soc Networks. (2015) 40:197-206. doi: 10.1016/j.socnet.2014.11.002

39. Reynolds AD, Crea TM. The integration of immigrant youth in schools and friendship networks. Popul Res Policy Rev. (2017) 36:501-29. doi: 10.1007/s11113-017-9434-4

40. Wessendorf S, Phillimore J. New migrants' social integration, embedding and emplacement in superdiverse contexts. Sociology. (2019) 53:123-38. doi: $10.1177 / 0038038518771843$

41. Décieux JP, Mörchen L. Emigration, friends, and social integration: the determinants and development of friendship network size after arrival. In: Erlinghagen M, Ette A, Schneider NF, Witte N. The Global Lives of Germany Migrants - Consequences of International Migration Across the Life Course. Cham: Springer. (2021) 41:247-64. doi: 10.1007/978-3-030-6749 8-4_14

42. Gericke D, Burmeister A, Lowe J, Deller J, Pundt L. How do refugees use their social capital for successful labor market integration? An exploratory analysis in Germany. J Vocat Behav. (2018) 105:46-61. doi: 10.1016/j.jvb.2017. 12.002

43. Schmidt K, Jacobsen J, Krieger M. Social Integration of Refugees is Improving Berlin (2020).

44. Strømme EM, Haj-Younes J, Hasha W, Fadnes LT, Kumar B, Igland $J$, et al. Health status and use of medication and their association with migration related exposures among Syrian refugees in Lebanon and Norway: a cross-sectional study. BMC Public Health. (2020) 20:341. doi: 10.1186/s12889-020-8376-7

45. Norwegian Institute of Public Health. Mental Illness Among Adults. (2016). Available online at: https://www.fhi.no/en/op/hin/mental-health/psykiskhelse-hos-voksne/ (accessed October 22, 2020).

46. Lassemo E, Sandanger I, Nygard JF, Sorgaard KW. The epidemiology of posttraumatic stress disorder in Norway: trauma characteristics and pre-existing psychiatric disorders. Soc Psychiatry Psychiatric Epidemiol. (2017) 52:11-19. doi: 10.1007/s00127-016-1295-3

47. Babitsch B, Gohl D, Von Lengerke T. Re-revisiting Andersen's Behavioral Model of Health Services use: a systematic review of studies from 1998-2011. GMS Psycho Soc Med. (2012) 9:1-15. doi: 10.3205/psm000089

48. Johnson KL, Carroll JF, Fulda KG, Cardarelli K, Cardarelli R. Acculturation and self- reported health among Hispanics using a socio- behavioral model: the North Texas Healthy Heart Study. Bmc Public Health. (2010) 10:53. doi: 10.1186/1471-2458-10-53

49. Magaard JL, Seeralan T, Schulz H, Brutt AL. Factors associated with helpseeking behaviour among individuals with major depression: a systematic review. PLoS ONE. (2017) 12:e0176730. doi: 10.1371/journal.pone.0176730

50. Li J, Maxwell AE, Glenn BA, Herrmann AK, Chang LC, Crespi CM, et al. Healthcare access and utilization among Korean Americans - the mediating role of english use and proficiency. Int J Soc Sci Res. (2016) 4:83-87. doi: $10.5296 /$ ijssr.v4i1.8678

51. Palinkas LA, Horwitz SM, Green CA, Wisdom JP, Duan N, Hoagwood K. Purposeful sampling for qualitative data collection and analysis in mixed method implementation research. Admin Policy Mental Health Mental Health Serv Res. (2015) 42:533-44. doi: 10.1007/s10488-0130528-y 
52. Statistics Norway. Rekordmange har kommet fra Syria siste par år. (2017). Available online at: https://www.ssb.no/befolkning/artikler-og-publikasjoner/ rekordmange-har-kommet-fra-syria-siste-par-ar-331535 (accessed June 04, 2021).

53. Faul F, Erdfelder E, Lang AG, Buchner A. G*Power 3: A flexible statistical power analysis program for the social, behavioral, biomedical sciences. Behav Res Methods. (2007) 39:175-91. doi: 10.3758/BF03193146

54. World Health Organization. The ICD-10 Classification of Mental and Behavioural Disorders: Diagnostic Criteria for Research. Albany, NY: World Health Organization (1993).

55. American Psychiatric Association. Diagnostic and Statistical Manual of Mental Disorders (DSM-5®)). Arlington, TX: American Psychiatric Pub (2013). doi: 10.1176/appi.books.9780890425596

56. Markova V, Sandal GM. Lay explanatory models of depression and preferred coping strategies among somali refugees in Norway. a mixed-method study. Front Psychol. (2016) 7:1435. doi: 10.3389/fpsyg.2016.01435

57. Erdal K, Singh N, Tardif A. Attitudes about depression and its treatment among mental health professionals, lay persons and immigrants and refugees in Norway. J Affect Disord. (2011) 133:481-8. doi: 10.1016/j.jad.2011.04.038

58. Wilson CJ, Deane FP, Ciarrochi JV, Rickwood D. Measuring help seeking intentions: properties of the general help seeking questionnaire. Canad $J$ Counsell. (2005) 39:15-28. doi: 10.1037/t42876-000

59. D'avanzo CE. Barriers to health care for Vietnamese refugees. J Profess Nurs. (1992) 8:245-53. doi: 10.1016/8755-7223(92)90086-E

60. Wong EC, Marshall GN, Schell TL, Elliott MN, Hambarsoomians K, Chun A, et al. Barriers to mental health care utilization for US Cambodian refugees. $J$ Consult Clin Psychol. (2006) 74:1116-20. doi: 10.1037/0022-006X.74.6.1116

61. Bhatia R, Wallace P. Experiences of refugees and asylum seekers in general practice: a qualitative study. BMC Family Pract. (2007) 8:48. doi: 10.1186/1471-2296-8-48

62. O'donnell CA, Higgins M, Chauhan R, Mullen K. “They think we're OK and we know we're not". a qualitative study of asylum seekers' access, knowledge and views to health care in the UK. BMC Health Serv Res. (2007) 7:75. doi: 10.1186/1472-6963-7-75

63. Byrow Y, Pajak R, Specker P, Nickerson A. Perceptions of mental health and perceived barriers to mental health help-seeking amongst refugees: a systematic review. Clin Psychol Rev. (2020) 75:101812. doi: 10.1016/j.cpr.2019.101812

64. Taber KS. The use of cronbach's alpha when developing and reporting research instruments in science education. Res Sci Educ. (2018) 48:1273-96. doi: 10.1007/s11165-016-9602-2

65. Haj-Younes J, Stromme EM, Igland J, Kumar B, Abildsnes E, Hasha W, et al. Changes in self-rated health and quality of life among Syrian refugees migrating to Norway: a prospective longitudinal study. Int J Equity Health. (2020) 19:188. doi: 10.1186/s12939-020-01300-6

66. Dowling A, Enticott J, Russell G. Measuring self-rated health status among resettled adult refugee populations to inform practice and policy - a scoping review. BMC Health Serv Res. (2017) 17:817. doi: 10.1186/s12913-017-2771-5

67. Derogatis LR, Lipman RS, Rickels K, Uhlenhuth EH, Covi L. Hopkins Symptom Checklist (HSCL) - self-report symptom inventory. Behav Sci. (1974) 19:1-15. doi: 10.1002/bs.3830190102

68. Sandanger I, Moum T, Ingebrigtsen G, Dalgard OS, Sorensen T, Bruusgaard D. Concordance between symptom screening and diagnostic procedure: the Hopkins Symptom Checklist-25 and the Composite International
Diagnostic Interview I. Soc Psychiatry Psychiatric Epidemiol. (1998) 33:345-54. doi: $10.1007 / \mathrm{s} 001270050064$

69. Selmo P, Koch T, Brand J, Wagner B, Knaevelsrud C. Psychometric properties of the online arabic versions of BDI-II, HSCL-25, and PDS. Europ J Psychol Assess. (2019) 35:46-54. doi: 10.1027/1015-5759/a000367

70. Ventevogel P, De Vries G, Scholte WF, Shinwari NR, Faiz H, Nassery R, et al. Properties of the Hopkins Symptom Checklist-25 (HSCL-25) and the SelfReporting Questionnaire (SRQ-20) as screening instruments used in primary care in Afghanistan. Soc Psychiatry Psychiatric Epidemiol. (2007) 42:328-35. doi: 10.1007/s00127-007-0161-8

71. World Medical Association. World Medical Association Declaration of Helsinki: ethical principles for medical research involving human subjects. JAMA. (2013) 310:2191-4. doi: 10.1001/jama.2013.281053

72. Atallah IE. The relationship between acculturation, trauma, and readiness to change among Arab refugees. Doctor of Philosophy, Northcentral University, San Diego, CA (2017).

73. Koenig HG. Religion and Mental Health: Research and Clinical Applications. Academic Press (2018).

74. Harris SM, Binder PE, Sandal GM. General practitioners' experiences of clinical consultations with refugees suffering from mental health problems. Front Psychol. (2020) 11:412. doi: 10.3389/fpsyg.2020.00412

75. O'connor PJ, Martin B, Weeks CS, Ong L. Factors that influence young people's mental health help-seeking behaviour: a study based on the Health Belief Model. J Adv Nurs. (2014) 70:2577-87. doi: 10.1111/jan.12423

76. Tip LK, Brown R, Morrice L, Collyer M, Easterbrook MJ. Improving refugee well-being with better language skills and more intergroup contact. Soc Psychol Personal Sci. (2019) 10:144-51. doi: 10.1177/1948550617752062

77. Fuller KL. Refugee mental-health in aalborg, denmark - traumatic stress and cross-cultural treatment issues. Nordic J Psychiatry. (1993) 47:251-6. doi: 10.3109/08039489309103334

78. Scheel AM, Tiokhin L, Isager PM, Lakens D. Why hypothesis testers should spend less time testing hypotheses. Perspect Psychol Sci. (2020) 16:744-55. doi: 10.31234/osf.io/vekpu

79. Wikberg A, Eriksson K. Intercultural caring - an abductive model. Scand J Caring Sci. (2008) 22:485-96. doi: 10.1111/j.1471-6712.2007.00555.x

Conflict of Interest: The authors declare that the research was conducted in the absence of any commercial or financial relationships that could be construed as a potential conflict of interest.

Publisher's Note: All claims expressed in this article are solely those of the authors and do not necessarily represent those of their affiliated organizations, or those of the publisher, the editors and the reviewers. Any product that may be evaluated in this article, or claim that may be made by its manufacturer, is not guaranteed or endorsed by the publisher.

Copyright (C) 2021 Harris, Sandal, Bye, Palinkas and Binder. This is an open-access article distributed under the terms of the Creative Commons Attribution License (CC $B Y)$. The use, distribution or reproduction in other forums is permitted, provided the original author(s) and the copyright owner(s) are credited and that the original publication in this journal is cited, in accordance with accepted academic practice. No use, distribution or reproduction is permitted which does not comply with these terms. 